\title{
Efficient and successfull design methods and tools for sustainable industrial systems
}

\author{
Dominique Millet $^{1} \cdot$ Nicolas Perry $^{2} \cdot$ Stephane LePochat $^{3} \cdot$ Sebastien Zinck $^{4}$. \\ Yann Leroy ${ }^{5}$
}

Published online: 1 June 2016

(C) Springer-Verlag France 2016

The thematic of this session was related to Sustainable Design of Industrial Systems and LCA based indicators in product development.

Sustainable design is of high interest. Indeed, customers' expectations, legislation and market pressure are some drivers which move design teams to take into consideration sustainable dimensions throughout the lifecycle of an industrial system. However, such an issue requires the integration of additional parameters into decision-making processes. Sustainable design of industrial systems now requests to solve methodological issues related to economic, social and environmental evaluations (system boundaries, functional analysis, impacts categories) and their integration into design process. New approaches, methods and tools dealing with such issues with industrial connections, have been presented during this session.

The present edition of the International Journal on Interactive Design and Manufacturing is supported by EcoSD (Ecodesign of Systems for a sustainable Development), the association which organized and supported the session "Efficient and successful design methods and tools for sustainable industrial systems" during the Life Cycle Management Conference LCM 2015 in Bordeaux.

Nicolas Perry

nicolas.perry@u-bordeaux.fr

1 Avenue de l'université, COSMER, University of Toulon, 83000 Toulon, France

2 I2M-UMR 5295-Arts et Métiers ParisTech, 3400 Talence, France

3 EVEA, 56 bd. de la Fraternité, 44100 Nantes, France

4 Steelcase, 67000 Strasbourg, France

5 Laboratoire Genie Industriel, CentraleSupélec, Université Paris-Saclay, 92290 Chatenay-Malabry, France
This thematic session was organized in connection with the EcoSD French network whose main objective is to encourage collaboration between academic and industrial researchers so they may create and spread advanced and multidisciplinary knowledge in the ecodesign fields at national and international levels.

Several other actions are proposed by the EcoSD network with the support of the French Environment and Energy Management Agency (ADEME), and the French Ministry of Higher Education and Research as well as the Ministry of Industry:

- Structuring EcoSD research activities in France to take advantage of the expertise of more than 200 members of this research network;

- Developing knowledge among researchers within the ecodesign field, and especially by better training $\mathrm{PhD}$ students by organizing relevant courses on this theme;

- Elaborating new methods, tools and databases compatible with sustainable development, in order to achieve complex systems design;

- Initiating the EcoSD label to acknowledge the quality and inclusion of sustainable development in training courses, research programs, research projects and symposiums;

- Enabling interactive collaborations between researchers and industrial partners through the financial support of Collaborative Research Projects, the organization of quarterly Research Seminars in Paris and an Annual Thematic Workshop.

Around 46 proposals (as papers or posters) from industry, academic and governmental institutions have participated to this special session in LCM 2015. Two sessions presented 14 papers completed with 32 posters. This thematic issue 
contains a synthesis of the contributions presented during this Conference.

We are very grateful to the organization committee for the perfect organization of the conference held in Bordeaux in August 2015. I also thank all the speakers for the quality of their presentations and the fruitful exchanges that followed.

Pr. Dominique MILLET, Seatech (President of EcoSD Network)
Co-Chairs of the LCM 2015 session: Efficient and successful design methods and tools for sustainable industrial systems: Dr. Stephane Lepochat, Evea; Pr. Nicolas Perry, ENSAM; Sebastien Zinck, Steelcase; Dr. Yann LeroY, Centrale Paris 